\title{
TÉCNICAS DE TRADUÇÃO DE UNIDADES FRASEOLÓGICAS EM TEXTOS JORNALÍSTICOS (ESPANHOL-PORTUGUÊS)
}

\author{
Flávia Andressa da Silva Santos* \\ Universidade Estadual Paulista "Júlio de Mesquita Filho" \\ Angélica Karim Garcia Simão** \\ Universidade Estadual Paulista "Júlio de Mesquita Filho"
}

\begin{abstract}
Resumo: O presente artigo destina-se a discutir a tradução de unidades fraseológicas (UFs) de um corpus paralelo bilíngue (espanhol-português), composto por textos jornalísticos extraídos do jornal El País espanhol e suas respectivas traduções para o português brasileiro publicadas no site da UOL (Notícias/Internacional), no período de janeiro de 2011. A análise tem como foco as estratégias e técnicas de tradução utilizadas, bem como os possíveis efeitos de sentido observados no texto de chegada. Para tanto, a reflexão proposta aqui discute e apoia-se nos conceitos de método, estratégias e técnicas de tradução, situando nossa análise na interface entre os Estudos da Tradução e a Fraseologia bilíngue. Nessa perspectiva, entende-se a Tradução como um processo comunicativo, textual e cognitivo e as UFs como unidades léxicas formadas por mais de
\end{abstract}

\footnotetext{
* Flávia Andressa da Silva Santos. Formada em Letras com Habilitação de Tradutor pela Universidade Estadual Paulista "Júlio de Mesquita Filho" (IBILCE/ Unesp). São José do Rio Preto, São Paulo, Brasil. E-mail: flaviasantos.trad@ gmail.com

** Angélica Karim Garcia Simão. Doutora em Letras pela Universidade de São Paulo (USP). Professor assistente doutor no curso de Bacharelado em Letras com Habilitação de Tradutor pela Universidade Estadual Paulista "Júlio de Mesquita Filho" (IBILCE/Unesp). São José do Rio Preto, São Paulo, Brasil. E-mail: angelica@ibilce.unesp.br
} 
duas palavras gráficas em seu limite inferior, cujo limite superior situa-se no nível da oração composta. A análise da tradução permitiu constatar o esvaziamento dos sentidos propostos nos textos de partida em função do uso excessivo de traduções literais em vez de equivalentes consagrados na língua de chegada.

Palavras-chave: Técnicas de tradução. Fraseologia bilíngue. Texto jornalístico. Língua espanhola.

\title{
TRANSLATION TECHNIQUES OF PHRASEOLOGICAL UNITS IN JOURNALISTIC TEXTS (SPANISH-PORTUGUESE)
}

\begin{abstract}
This article aims to discuss the translation of phraseological units contained in a parallel bilingual corpus (Spanish-Portuguese) composed of journalistic texts taken from El País, Spanish newspaper, and their respective translations into Brazilian Portuguese published on UOL website (News/International) in January 2011. The analysis has as focus translation strategies and techniques used, as well as possible meaning effects observed in the target text. Thus, the reflection herein proposed discusses and is founded on the concepts of translation method, strategies, and techniques, situating our analysis in the field between Translation Studies and Bilingual Phraseology. Such perspective understands Translation as a communicative, textual and cognitive process, and phraseological units as lexical units made up of more than two graphic words in their lower limit, whose upper limit is located at the compound clause level. The translation analysis displayed the emptying of senses proposed in the source texts due to an excessive use of literal translations instead of well-known equivalents in the target language.
\end{abstract}

Keywords: Translation techniques. Bilingual phraseology. Journalistic text. Spanish language.

\section{Introdução}

Quando falamos de textos jornalísticos nos referimos, na realidade, a uma grande quantidade de gêneros ou tipologias textuais diversificadas, embora majoritariamente a função de todos eles possa ser restrita a uma só: informar. Daí os manuais de redação e estilo enfocarem as recomendações de clareza, concisão, precisão, 
fluência e simplicidade, recomendações essas que também servem para o tradutor ao desenvolver sua tarefa com essa tipologia textual (HERNÁNDEZ GUERRERO, 2006).

Sabemos, contudo, que tanto o fato de exigir que um texto se enquadre dentro de uma tipologia única, quanto o de exigir que esse texto seja preciso e objetivo, dentre outras características idealizadas, é utópico e a própria hibridização das tipologias textuais jornalísticas aponta para isso. A linguagem jornalística, por ter registros amplos, é determinada por estilos e linguagens diferenciados decorrentes dos públicos, dos meios, das temáticas, dos perfis editoriais e de seus realizadores. (Cf. RODRIGUES BETANCOURT, 2004, p.327).

Entende-se que o texto jornalístico, particularmente o de caráter informativo, abordado no presente artigo, e que se distingue do jornalismo de opinião, conforme divisão seguida por Díaz Noci (2000), por ter a função básica de informar fatos do cotidiano à sociedade, deve ser apresentado com uma linguagem simples, acessível, sem rebuscamentos, que cumpra com o seu objetivo fundamental que é o de reportar acontecimentos relevantes à população. Devido a tal objetivo, durante muito tempo o fazer jornalístico foi visto do ponto de vista da objetividade, da neutralidade e da imparcialidade, termos que vinham sendo amplamente utilizados como seus definidores, mas que, nos últimos tempos, passaram a ser repensados.

A imprensa é considerada por muitos autores que rejeitam a ideia anterior como uma instituição social que reporta os fatos de um mundo exterior e, como tal, recebe influências externas que ditarão, por sua vez, o que será noticiado e como o fato será abordado (ZIPSER, POLCHLOPEK, 2009). Assim como o relato do fato noticioso não está isento das influências externas que regem a imprensa, anulando a visão de imparcialidade e objetividade, à tradução que será feita deste texto também não caberá uma definição que compreenda esses termos.

Sobre os aspectos que envolvem o jornalismo Zipser e Polchlopek (2009, p. 204) resumem a sistematização feita por Frank 
Esser, chamada de Modelo Pluriestratificado Integrado, ou Metáfora da Cebola:

\begin{abstract}
Segundo o modelo, aspectos sociais, políticos, normativos e subjetivos emolduram e interagem de forma dinâmica no espaço da prática jornalística sempre permeados pela ética, sendo específicos a cada contexto cultural. Tal perspectiva questiona a visão consensual do compromisso jornalístico com a neutralidade, a transcodificação isenta que desconsidera o dinamismo da linguagem e os fatores que influenciam o processo de formação de sentido dos textos.
\end{abstract}

Um texto a ser traduzido voltar-se-á a um público alvo diferente daquele ao qual se destinava o original, o que configura uma situação nova marcada pela distância espacial-geográfica, resultando, portanto, numa diferença entre diferentes leitores inseridos em diferentes culturas. Em suma, da mesma forma que a neutralidade, atrelada à imparcialidade, não é um aspecto inerente ao jornalismo, a tradução não poderá ser considerada como uma atividade puramente mecânica e neutra.

Sendo assim, os textos jornalísticos, que já são fruto de uma transformação inicial, a do fato para a notícia, passam também por transformações ao serem traduzidos de uma cultura à outra, motivadas por condicionantes não só estilísticos, mas também e, principalmente, sociais, culturais e políticos, sobre os quais o tradutor pode ter consciência ou não.

Dessa forma, é o objetivo deste artigo apresentar e discutir certas escolhas feitas pelo tradutor das notícias do corpus em questão com relação à tradução de unidades fraseológicas, por serem esses elementos da língua frequentemente embutidos de caráter cultural e que, portanto, necessitam, em determinados contextos de uso, de adequações quando da tradução para uma língua estrangeira. 


\section{Sobre o corpus utilizado na pesquisa}

Essa pesquisa é parte integrante de um projeto mais abrangente, caracterizado pelo levantamento e análise de técnicas de tradução presentes em um corpus paralelo bilíngue (espanhol-português) composto por textos jornalísticos, compilado para o uso com fins investigativos de pesquisa e análise ${ }^{1}$.

Compõe-se de um total de 44 textos escritos extraídos do jornal espanhol El País, em sua versão eletrônica (http://www.elpais. com), e suas respectivas traduções para o português brasileiro, disponibilizadas diariamente no site da UOL - Notícias/Internacional (http://www.uol.com.br). Os textos referem-se ao período de publicação de 3 a 30 de janeiro de 2011 e totalizam 86.910 palavras.

Trata-se de um corpus de textos escritos autênticos (Sardinha, 2004), especializado, pois pertencem especificamente ao gênero jornalístico de caráter informativo, cuja autoria é atribuída a vários autores diferentes, porém, traduzidos para a língua de chegada por um único tradutor, Luiz Roberto Mendes Gonçalves.

\section{Tradução de unidades fraseológicas}

Ao se referir à tradução dos gêneros jornalísticos, Osimo (2000) diz que a tradução na imprensa possui características que em muito a distinguem da tradução da não ficção geral. A princípio pode-se pensar que a linguagem jornalística, por apresentar dados referentes aos fatos reais ou transmitir informação, seja puramente denotativa e relativamente fácil de ser traduzida no plano estilístico e sintático, suscitando, talvez, algumas dificuldades concernentes, no máximo, ao léxico.

Entretanto, o autor cita a heterogeneidade como um elemento constituinte dessa tipologia textual e atesta as dificuldades que o tradutor pode enfrentar ao se deparar com comentários políticos e com referências contextuais, muitas vezes implícitas nas coordenadas culturais, além do léxico local e do caráter ensaístico que 
adquirem alguns textos dessa natureza. Consideramos que as UFs como elementos culturais, muitas vezes com acentuado grau de conotação, sejam também constituintes dessa heterogeneidade do texto jornalístico, daí o enfoque de nossa pesquisa.

As UFs são combinações estáveis de unidades léxicas constituídas por duas ou mais palavras gráficas em seu limite inferior, cujo limite superior situa-se no nível da oração composta (CORPAS PASTOR, 1996). Por apresentarem cristalização morfológica e semântica e, em alguns casos, um elevado grau de idiomaticidade, tais estruturas não podem ser traduzidas literalmente, uma vez que o seu conteúdo semântico não é resultado da soma de seus componentes, princípio da indecomponibilidade (XATARA, RIVA e RIOS, 2002).

Corpas Pastor (1996), de uma perspectiva ampla da Fraseologia, considera UFs as colocações, as locuções e os enunciados fraseológicos, embora atribua para cada uma delas níveis diferentes de idiomaticidade, isto é, considera que podem apresentar diferentes graus de conotação, sendo algumas mais opacas e outras mais transparentes em termos semânticos.

A idiomaticidade, denominada indecomponibilidade ou não composicionalidade semântica (PAMIES, 2007), é considerada, com frequência, um traço essencial das UFs e que impõe dificuldades extras à interpretação e à tradução. Com o intuito de verificar tais aspectos propomos, a partir da próxima seção, a análise das UFs levantadas no corpus já mencionado à luz das técnicas de tradução propostas por Hurtado Albir (2001).

\section{Aspectos metodológicos e análise dos dados}

Os procedimentos envolvidos na tradução foram pesquisados incialmente no final da década de 50, pelos teóricos franceses Vinay e Darbelnet (1958), os quais propuseram 7 procedimentos orientados pelos paradigmas dicotômicos tradução literal ou direta e tradução oblíqua ou livre. 
No Brasil, somente nos anos 80 e 90, esses conceitos foram revisados e receberam novas interpretações. Aubert (1998) iniciou os trabalhos, pioneiramente, propondo 13 "modalidades tradutórias". Posteriormente, Barbosa (1990) denominou-os "procedimentos técnicos de tradução", título de sua dissertação de mestrado, na qual a pesquisadora foge da dicotomia proposta pelos franceses, propondo 15 procedimentos tradutórios considerados equânimes ${ }^{2}$.

Em 2001, Hurtado Albir retoma novamente o conceito proposto pelos teóricos franceses, traçando uma distinção entre método, estratégias e técnicas. Como técnica ela entende o procedimento verbal concreto, visível no resultado da tradução a fim de obter equivalências tradutórias, e que afetam zonas menores do texto. Diferentemente do método, que é uma opção global que percorre todo o texto e afeta tanto o processo, como o resultado final, e as estratégias, que podem ser não verbais e são utilizadas durante todas as fases do processo de tradução para a resolução de problemas, as técnicas são concretas e visíveis no texto traduzido como resultado da escolha do tradutor.

Baseados no conceito de técnica e no que a autora entende como tradução literal e equivalente consagrado, analisamos os dados abaixo, considerando que estas foram as duas técnicas empregados pelo tradutor para a tradução das UFs no corpus analisado.

\section{Traduções literais}

A técnica de tradução literal é aqui entendida como sendo uma tradução palavra por palavra ${ }^{3}$ de um sintagma ou expressão. Devido à proximidade linguística entre o português e o espanhol, a maior parte das matérias traduzidas pertencentes ao corpus selecionado seria considerada tradução literal. Entretanto, para esta análise, selecionamos para análise o emprego desta técnica apenas para os casos de traduções de unidades fraseológicas, conforme dito anteriormente. 
A tradução literal de algumas unidades fraseológicas produziu expressões que, embora permitam a inferência de seu significado, não soam de forma natural para um leitor brasileiro, pois não retomam os sentidos figurados existentes em tais expressões. Vejamos os exemplos abaixo (os casos são apresentados pelas datas de publicação das traduções para o português no site da UOL).

\section{$04 / 01 / 2011$}

La nueva presidenta -junto con Cristina Fernández en Argentina y Laura Chinchilla en Costa Ricaes la tercera jefa de Estado en ejercicio de América Latina. Juega con las cartas contra el pecho, sin decir más que generalidades sobre sus intenciones.
A nova presidente - junto com Cristina Fernández na Argentina e Laura Chinchilla na Costa Rica - é a terceira chefe de Estado mulher em exercício na América Latina. Joga com as cartas contra o peito, sem dizer mais que generalidades sobre suas intenções.

A locução verbal "jugar con las cartas contra el pecho" se assemelha a outras UFs bastante frequentes na língua espanhola, como as locuções verbais "ponerle a alguien las cartas boca arriba" e "conocer las cartas a alguien" ou sua sinônima "conocerle el juego". Todas elas têm o sentido de conhecer as intenções de alguém ou saber quais são os seus propósitos, referem-se a estratégias de comportamento ou ação em determinada situação. Uma outra locução verbal "jugar a cartas vistas" parece opor-se semanticamente à locução apresentada, com o significado no português de revelar suas intenções ou "abrir o jogo". De um modo geral, a locução "jugar con las cartas contra el pecho" remete a ideia de dissimulação ou da falta de intenção em revelar ideias ou propósitos secretos. Dessa forma, seu significado poderia ser retomado, ao ser traduzido para o português, pelos equivalentes de uso consagrados correspondentes: "esconder o jogo", "esconder o leite”, ou até "esconder o ouro". 


\section{6/01/2011}

"Al maltratador grave le importa poco la pena que se le pueda imponer, entre otras cosas porque muchos se suicidan. $Y$ aún le importa mucho menos tener una orden de alejamiento si al final acaba en papel mojado", recuerda García Arán.

"Ao agressor pouco importa a pena que possa lhe ser imposta, entre outras coisas porque muitos se suicidam. E importa muito menos ter uma ordem de afastamento, se no final acaba em papel molhado", lembra García Arán.

O mesmo acontece com a locução nominal "papel mojado", cujo significado figurado e coloquial é apresentado pelo DRAE como "de pouca importância ou prova para determinado assunto", e pelo DUE como "qualquer coisa de pouca importância ou cuja eficácia é nula”. Na língua portuguesa, pode-se citar a UF “acabar em pizza", cujo significado é atrelado à falta de punição dos implicados em uma investigação e costuma ser estendido ao uso mais amplo em situações em que algo não causa resultados efetivos. Outra UF que também pode ser equivalente a essa, em termos de significado, seria "não dar em nada".

\section{$08 / 01 / 2011$}

La agencia atendió igualmente la reclamación de un hombre a quien le fue notificada a través del boletín oficial de su provincia una multa por hacer "aguas menores" en la calle.
A agência também atendeu à reclamação de um homem a quem foi notificada através do boletim oficial de sua província uma multa por fazer "águas menores" na rua.

A locução nominal "aguas menores", cuja tradução literal remete a uma UF inexistente na língua portuguesa, pode ser retomada pela UF equivalente em termos de uso "fazer xixi", pela forma mais vulgar "tirar água do joelho", ou simplesmente pelo verbo "urinar". 


\section{9/01/2011}

La sabiduría popular, la más afectada por las feroces guerras de religión que asolaron Europa durante siglos, acuñó la expresión " $Y Y$ se armó la de Dios es Cristo!", para escenificar las consecuencias de las disputas teológicas sobre si Jesús de Nazaret era hijo de Dios, y no un simple mesías.

A sabedoria popular, a mais afetada pelas ferozes guerras de religião que assolaram a Europa durante séculos, cunhou a expressão " $E$ se armou a de Deus é Cristo" [um grande alvoroço] para representar as consequências das disputas teológicas sobre se Jesus de Nazaré era filho de Deus e não um simples Messias.

A matéria original lança mão de um enunciado fraseológico consagrado em espanhol peninsular. A solução encontrada foi fazer a tradução literal e, então, apresentar em seguida uma breve explicação sobre seu significado. Para manter a analogia ao campo religioso e a referência a "Deus" presente na UF na língua de partida, havia a possibilidade de tradução por "e foi um Deus nos acuda" que para muitos outros contextos seria relevante, entretanto, neste caso, o uso de tal equivalente consagrado prejudicaria ou dificultaria a compreensão do texto.

\section{1/01/2011}

Además, muchos dudan de que Dilma Roussef, presidenta de Brasil desde el pasado día 1, ponga toda la carne en el asador por Graziano, cuya candidatura fue una apuesta personal de su predecesor, con quien mantiene una larga amistad.

Além disso, muitos duvidam de que Dilma Rousseff, a presidente do Brasil desde o último dia $1^{\circ}$, ponha toda a carne na grelha por Graziano, cuja candidatura foi uma aposta pessoal de seu antecessor, com quem mantém uma longa amizade.

A locução verbal "Poner toda la carne en el asador" é uma UF da língua espanhola com o significado de utilizar todos os re- 
cursos dos quais se dispõe para conseguir determinado propósito. Diante da ausência de uma UF semelhante em português, a opção do tradutor foi transpô-la literalmente, o que, aparentemente, não prejudica a compreensão da situação a qual essa expressão referese, pois, o contexto pode encarregar-se de situar o leitor. Entretanto, outros equivalentes de uso consagrados e mais estendidos em nosso contexto, como "apostar todas as fichas" ou até mesmo uma paráfrase como "arriscar tudo", poderiam retomar o sentido com mais objetividade.

\section{3/01/2011}

El Ejecutivo se guarda también un as en la manga: podrá fijar un precio máximo para las conexiones.

E o Executivo também guarda um ás na manga: poderá definir um preço máximo para as conexões.

A locução nominal "as en la manga" é uma UF espanhola que em português equivale a "Ter/esconder/guardar (uma) carta na manga", sendo a utilização do verbo "ter" mais usual. Retoma a ideia de "recurso oculto com o qual se pode vencer o adversário" (PENADÉS MARTINEZ, 2008). Considera-se a tradução apresentada no corpus em questão como literal devido à manutenção do vocábulo "ás". Apesar disso, uma vez que não se produzem mudanças significativas na tradução que pudessem obscurecer o sentido de dita UF, o leitor é capaz de interpretar a expressão como o fato de possuir um elemento chave para a resolução de um problema.

\section{6/01/2011}

Ciccone parafrasea un razonamiento que circula en la televisión de media tarde, en los reportajes de calle de los diarios y en la cafetería de la vuelta de la esquina.
Ciccone parafraseia um argumento que circula na televisão à tarde, nas reportagens de rua dos jornais e nos cafés de esquina. 
"A la vuelta de la esquina" é uma locução adverbial que, além de significar, literalmente, "o lado oposto da esquina em que se está", possui um sentido figurado, referindo-se a algo que seja bastante próximo ou acessível. Portanto, quando a matéria em espanhol traz "cafeteria de la vuelta de la esquina", não se está falando apenas de cafeterias localizadas na esquina de uma rua, mas de qualquer cafeteria.

Em português, seria uma construção do tipo "em qualquer esquina”, por exemplo, "Amigos de verdade não é uma coisa que você encontra em qualquer esquina”, ou seja, "esquina” aqui não faz referência a um local físico, mas imprime à sentença o sentido metafórico de que amigos de verdade não é algo fácil de se encontrar. A tradução para o português de "cafeteria de la vuelta de la esquina" foi "cafés de esquina", que parece não resgatar em sua totalidade o sentido figurado que a UF em espanhol conota.

$\mathrm{O}$ que parece estar em jogo nos excertos dos textos jornalísticos apresentados anteriormente relaciona-se com a carga metafórica que cada uma das UFs encerra. Da nossa perspectiva, as UFs com maior carga idiomática como "acabar en papel mojado" ou "hacer aguas menores", por exemplo, parecem, quando traduzidas literalmente, gerar estranhamento, senão incompreensão por parte de leitor na apreensão dos sentidos gerados pela leitura da tradução proposta. As UFs menos idiomáticas, como "jugar con las cartas contra el pecho" ou "poner todas las carnes al asador" talvez possibilitem que o leitor mais atento possa inferir os sentidos por meio de elementos presentes na UF.

\section{Equivalentes consagrados}

Hurtado Albir (2001) entende que a técnica de equivalente consagrado se consolida na tradução por meio da utilização de um termo ou expressão reconhecido como equivalente na língua de chegada por estar registrado em obras de referência ou no uso da língua. Ou seja, são os equivalentes que encontramos propostos 
pelos dicionários ou que são de conhecimento estendido na comunidade falante de determinado idioma.

Dada tal caracterização, essa pesquisa considera dita técnica como oposta à tradução literal, sobretudo no que concerne a tradução de UFs.

Diferentemente dos casos de traduções literais, houve momentos em que o tradutor, ao se deparar com UFs, optou pela utilização de equivalentes de uso consagrado.

\section{$03 / 01 / 2011$}

"La directora de una revista de automóviles, a la que amenacé con denunciar si de su chat no eliminaba algunos comentarios de usuarios sobre cómo evitar un control de alcohol, me conoció, eliminó el chat

"A diretora de uma revista de automóveis, à qual ameacei denunciar se não eliminasse de seu chat alguns comentários de usuário sobre como evitar o teste do 'bafômetro', me conheceu, eliminou o chat

É possível que uma tradução literal de "control de alcohol" fosse um tanto inadequada, apesar de o contexto da matéria dar indícios de seu significado. Uma vez que tanto o contexto espanhol quanto o contexto brasileiro possuem essa realidade de fiscalização de consumo de bebida alcoólica, "teste do bafômetro" é a tradução mais apropriada, já que este é o nome pelo qual ficou conhecido o teste de embriaguez em motoristas de todo o país, como exigência da "Lei seca".

\section{7/01/2011}

"Aquí podemos fumar, por pícaros", elogia entre una densa humareda Anton Tapias, presidente del primer club privado de fumadores inaugurado

"Aqui podemos fumar, por malandragem", elogia entre uma densa fumaceira Anton Tapias, presidente do primeiro clube privado de fumantes inaugurado 


\begin{tabular}{l|l|}
\hline $\begin{array}{l}\text { tras la reciente legislación } \\
\text { antitabaco.[...] Este centro }\end{array}$ & $\begin{array}{l}\text { depois da recente legislação } \\
\text { antitabaco. [...] O centro, com }\end{array}$ \\
de fumadores tiene ya unos & cerca de 40 sócios entre 450 \\
me socios de entre los 450 & membros do Círcol, estreia assim \\
miembros del Círcol y estrena & a malandragem para escapar às \\
así la picaresca para eludir las & restrições legais ao consumo \\
restricciones legales al consumo & de tabaco: a criação de clubes \\
de tabaco: la creación de clubes & privados de fumantes, nos \\
privados de fumadores en los que & quais a norma permite fumar. \\
la normativa en vigor permite & [...] Com esses precedentes, \\
fumar.[...] Con estos precedentes & parece difícil garantir que o \\
parece difícil garantizar que & local cumprirá as normas e os \\
el local cumplirá las normas y & garçons do Círcol, por exemplo, \\
los camareros del Círcol, por & não acabem esticando a mão \\
ejemplo, no acaben alargando la & para depositar a bebida nas \\
mano para depositar la bebida & mesas do Caliquenyo. "Isso não \\
en las mesas del Caliquenyo. & acontecerá”, afirma o presidente. \\
"Eso no ocurrirá", asegura el & Um verdadeiro malandro. \\
presidente. Todo un pícaro. &
\end{tabular}

Os três trechos anteriores, trazem a ocorrência da UF "por pícaro", desdobrada em "picaresca" e "todo un pícaro", em espanhol. Tais lexias poderiam ser traduzidas para o português, de forma literal, pois encontram-se dicionarizadas, sem mudança de sentido. No entanto, é possível que uma parcela do público-alvo não fosse capaz de reconhecê-las, pelo fato de não estar tão familiarizado com tais vocábulos que não são de amplo uso. Sendo assim, talvez com o objetivo de produzir um texto que seja culturalmente próximo ao leitor brasileiro, a estratégia do tradutor foi a de "domesticar" as lexias por seus equivalentes análogos "malandro" e "malandragem".

\section{2/01/2011}

[...] y la entrevista concedida por Ruby a un programa del Canale 5 dirigido por Alfonso

[...] e a entrevista concedida por Ruby a um programa do Canal 5 dirigido por Alfonso 
Signorini, director de la revista del corazón Chi [...] Su versión sigue al dedillo el ideario de los videomensajes y las declaraciones de Ruby.
Signorini, diretor da revista de fofocas "Chi" [...] Sua versão segue à risca o ideário das videomensagens e das declarações de Ruby.

A colocação "revista del corazón" refere-se a um elemento presente tanto na cultura espanhola quanto na cultura brasileira. Diz respeito, basicamente, a revistas que se ocupam da vida dos famosos, e que, geralmente, são lidas pelo público feminino. Talvez sejam essas motivações que levam o tradutor apresentar para esse tipo de publicação o equivalente "revista de fofoca". Já "al dedillo" é uma locução adverbial coloquial utilizada em espanhol para indicar que se aprendeu ou se sabe algo detalhadamente. A opção do tradutor foi traduzi-la por outra locução adverbial, "à risca". “Ao pé da letra" seria uma outra possibilidade.

\section{2/01/2011}

China se ha convertido, de la noche a la mañana, en el principal socio comercial de varios países latinoamericanos.
A China se transformou da noite para o dia no principal parceiro comercial de vários países latinoamericanos.

O equivalente empregado pelo tradutor para a expressão "de la noche a la mañana", foi "da noite para o dia", UF sinônima e o equivalente consagrado para a UF em espanhol. Neste caso, traduzir "mañana" por "manhã", não produziria uma expressão que, embora inteligível, soasse natural.

\section{Considerações finais}

As UFs encontradas nas matérias jornalísticas nos textos de partida foram tratadas basicamente de duas formas pelo tradutor: ou 
foram literalmente traduzidas, ou foram resgatadas semanticamente a partir da proposição de um equivalente de uso consagrado em português. A suposta proximidade linguística entre o português e o espanhol é responsável pela crença em uma certa facilidade e automatização na realização de traduções, porém vimos que tal proximidade não anula a necessidade de atenção durante o ato tradutório envolvendo ambas as línguas.

Um texto resultante de uma tradução, a depender dos recursos que o tradutor é capaz de ativar para solucionar alguns casos que requerem maior cuidado, pode fazer o leitor engajar-se numa leitura que lhe soe natural e fluida, ou, por outro lado, criar situações nas quais, se o sentido não acabar por ficar totalmente obscuro, no mínimo poderá gerar certo grau de estranheza ou confusão no leitor. Tal fato pode ser observado nos casos de traduções literais de UFs aqui apresentados.

No entanto, é interessante refletir sobre o exemplo de 09/01/2011, em que a UF “;Y se armó la de Dios es Cristo!” retoma, além da carga idiomática, também o componte histórico presente na UF. O uso dessa unidade, em sua esfera mais abstrata, nos permite argumentar que a possível tradução pelo equivalente consagrado (e se armou um Deus nos acuda) poderia gerar ao leitor mais obscurecimento e confusão. Dessa forma, nem sempre o uso de equivalentes consagrados é considerado ideal em qualquer situação tradutória, o que evidencia o fato de que não há normas definitivas e fixas para o ato tradutório e que a análise das funções comunicativas que as UFs exercem é sempre fundamental para a escolha dos equivalentes mais relevantes para cada contexto específico.

O emprego da tradução literal para uma UF deve, da nossa perspectiva, partir inicialmente da análise de sua carga metafórica, isto é, do grau de opacidade ou transparência semântica que a UF possui e, posteriormente, da adequação dos equivalentes de tradução ao público-alvo para o qual se dirige a tradução. Em se tratando do texto jornalístico, sabemos que esse público-alvo se refere a uma parcela muito ampla e heterogênea da sociedade, para a qual os objetivos de facilidade no processamento da informação são 
sempre almejados. Dessa forma, a facilidade ao acesso da informação será sempre desejada, em detrimento de seu rebuscamento ou ofuscamento.

Por outro lado, sabemos das imposições do mercado sobre os prazos que incidem e afetam diretamente o trabalho do tradutor, sobretudo na realidade profissional do tradutor de textos jornalísticos, na qual os fatos devem ser noticiados muito rapidamente. Nesse contexto, o fator tempo coloca em xeque a qualidade e primor de seu trabalho e dificulta seu rendimento, no que diz respeito à pesquisa e documentação. Nesse âmbito, as condições impostas à tarefa de tradução afetam diretamente a escolha das estratégias empregadas em seu ofício.

\section{Notas}

1. Pesquisa desenvolvida com apoio da FAPESP - Fundação de Amparo à Pesquisa do Estado de São Paulo (Processo 2011/19302-1).

2. Para uma revisão detalhada dos procedimentos, modalidades e técnicas tradutórias propostas por esses autores, confira Leivas Waquil (2013).

3. Para Hurtado Albir (2001), assim como para Vinay e Darbelnet (1958) e Aubert (1998), tradução literal e tradução palavra por palavra são sinônimas. Para Barbosa (1990) trata-se de procedimentos diferentes. 


\section{Referências}

AUBERT, F. H. Modalidades tradutórias: teoria e resultados. TradTerm. Revista do Centro Interdepartamental de Tradução e Terminologia. v. 5, n. 1, 1998, p. 99-128.

BARBOSA, H. G. Procedimentos técnicos da tradução. Campinas: Pontes, 1990.

CORPAS PASTOR, G. Manual de Fraseología espanhola. Madrid: Gredos, 1996.

DÍAZ NOCI, J. Las raíces de los géneros periodísticos interpretativos: precedentes históricos formales del reportaje y la entrevista. Estudios sobre el mensaje periodístico. $\mathrm{n}^{\mathrm{o}} 6,2000$, p. 135-152.

HERNÁNDEZ GUERRERO, M. J. Técnicas específicas de la traducción periodística. Quaderns. Revista de traducció. no 13, 2006, p. 125-139.

HURTADO ALBIR, A. Traducción y traductología: introducción a la Traductología. Madrid: Cátedra, 2001.

LEIVAS WAQUIL, M. Unidades fraseológicas especializadas e técnicas tradutórias. Debate Terminológico. N. 9, nov. 2013, p. 56-81.

PAMIES, A. De la idiomaticidad y sus paradojas. In: CONDE, G. (ed.) Nouveaux apports à létude des expressions figées. Cortil-Wodon (Belgique): InterCommunications \& E.M.E. Collection Promimités Didactique. 2007, p. 173-204.

PENADÉS MARTÍNEZ, INMACULADA. Diccionario de locuciones nominales, adjetivas y pronominales para la enseñanza del español. Madrid: Editorial Arco Libros, 2008.

RODRÍGUEZ BETANCOURT, M. Géneros periodísticos: para arropar su hibridez. Estudios sobre el mensaje periodístico. $\mathrm{n}^{\circ} 10,2004$, p. 319-328. 
OSIMO, B. Traducción periodística. Milão, 2000. Disponível em http://courses.logos.it/pls/dictionary/linguistic_resources.cap_4_27?lang =es Acesso: 20/07/2010.

SARDINHA, T. B. Linguística de Corpus. São Paulo: Editora Manole, 2004.

VINAY, J.P.; DARBELNET, J. Stylistique comparée du français et de l'anglais: méthode de traduction. Nouvelle édition revue et corrigée. Paris: Didier, 1958.

XATARA, C. M.; RIVA, H. C.; RIOS, T. H. C. As dificuldades na tradução de idiomatismos. Cadernos de Tradução, Florianópolis, NUT, v. 8, p. 183-194, 2002.

ZIPSER, M. E.; POLCHLOPEK, S. A. A interface tradução jornalismo: uma nova experiência em tradução. Eletras, vol. 18, n.18, jul.2009, p. 195- 210.

Recebido em: 12/07/2015

Aceito em: 08/09/2015 